\title{
Compreensões Probabilísticas de Crianças Brasileiras e Portuguesas Acerca de Justiça em Jogos
}

\section{Probabilistic Understandings of Brazilian and Portuguese Children about Fairness in Games}

\author{
Rita Batista ${ }^{\mathrm{a}}$; Ana Henriques ${ }^{\mathrm{b}}$; Rute Borba*c \\ a'Universidade Federal de Pernambuco, Programa de Pós-Graduação Stricto Sensu em Educação Matemática e Tecnológica. PE, Brasil. \\ bInstituto de Educação, Universidade de Lisboa. Portugal. \\ 'Universidade Federal de Pernambuco. PE, Brasil. \\ *E-mail: resrborba@gmail.com
}

\begin{abstract}
Resumo
Frequentes dificuldades na compreensão probabilística exigem que se identifiquem crenças intuitivas das crianças para apoiar a promoção pedagógica dessas aprendizagens. O presente estudo versa analisar as compreensões de crianças brasileiras e portuguesas acerca de justiça em jogos, considerando demandas cognitivas da probabilidade referentes à aleatoriedade, ao espaço amostral e à comparação de probabilidades. A pesquisa envolveu a análise de seis jogos e foi realizada por meio de uma entrevista clínica com 15 crianças brasileiras e 15 portuguesas, com média de idade de 11 anos. Os resultados revelam que as crianças apresentaram facilidade em avaliar um jogo injusto quando envolvia aleatorizadores viciados e em perceber a justiça num jogo cujas regras mantinham equilíbrio, permitindo que houvesse chances iguais para os jogadores. No entanto, observou-se que apresentaram incompreensões acerca da independência de eventos, conduzindo a avaliações equivocadas sobre a justiça em jogos. Nenhuma criança conseguiu apresentar justificativa coerente quando necessário comparar probabilidades considerando eventos de espaços amostrais distintos. Também não conseguiram utilizar o raciocínio proporcional, e, portanto, não avaliaram corretamente a justiça nesses jogos. Finalmente, os resultados não apontam para diferenças substanciais nas compreensões dos dois grupos estudados. Só em termos de linguagem, as expressões mais utilizadas nas justificativas por ambos os grupos foi 'chance', mas as crianças brasileiras usaram mais a 'sorte' e as portuguesas os termos 'possibilidade' e 'probabilidade'. Estes resultados implicam a necessidade de viabilizar ações pedagógicas interventivas realizadas com o apoio de jogos que se configuram num importante recurso para o redimensionamento das aprendizagens probabilísticas.
\end{abstract}

Palavras-chave: Aleatoriedade. Espaço Amostral. Comparação de Probabilidades. Justiça em Jogos. Crianças.

\begin{abstract}
Frequent difficulties in probabilistic understanding require the identification of children's intuitive beliefs to support the pedagogical promotion of these learnings. The present study focuses on analyzing Brazilian and Portuguese children understandings about fairness in games, considering cognitive demands of probability regarding randomness, sample space and comparison of probabilities. The research involved the analysis of six games and was carried out through a clinical interview with 15 Brazilian and 15 Portuguese children, with an average age of 11 years. The results reveal that the children were able to evaluate an unfair game when it involved addicted randomizers and to perceive justice in a game whose rules maintained balance, allowing the players to have equal chances. However, it was observed that they presented misunderstandings about the independence of events, leading to mistaken assessments of fairness in games. No child was able to present a coherent justification when there was a need to compare probabilities considering events from different sample spaces. They were also unable to use proportional reasoning, and therefore did not correctly assess justice in these games. Finally, the results do not point to substantial differences in the understandings of the two groups studied. Only in the language, the most used expressions in the justifications by both groups was 'chance', although Brazilian children used more 'luck' and Portuguese used 'possibility' and 'probability'. These results imply the need to make feasible interventional pedagogical actions carried out with the support of games which are an important resource for the resizing of probabilistic learning.
\end{abstract}

Keywords: Randomness. Sample Space. Comparison of Probabilities. Fairness in Games. Children.

\section{Introdução}

Nas últimas décadas o ensino da probabilidade tem ganhado saliência na Educação Matemática, como enfatizado em documentos curriculares em diversos países (Brasil, 2017, 2018; Franklin et al., 2007, NCTM, 2000) e por diversos pesquisadores (Bryant \& Nunes, 2012; Borovnick \& Kapadia, 2010; Batanero et al., 2016; Gal, 2004), que estabelecem a importância dos alunos explorarem conhecimentos probabilísticos desde os anos iniciais de escolarização, para que se construa de forma processual e contínua o pensamento probabilístico.

Historicamente a probabilidade está associada aos jogos de azar, mas atualmente o seu papel instrumental na aprendizagem de diversos conhecimentos curriculares é amplamente reconhecido, assim como sua aplicação em variados fenômenos do cotidiano que envolvem a incerteza e a previsão de acontecimentos. Também é particularmente importante em função da literacia estatística necessária ao cidadão moderno, para compreender qualquer procedimento 
inferencial estatístico e os conceitos de risco, além de oferecer uma ferramenta para modelação e criação da realidade (Borovcnik \& Kapadia, 2010; Bryant \& Nunes, 2012).

No entanto, segundo os autores, há pessoas com bastante dificuldade em pensar racionalmente sobre probabilidade, pois as suas intuições primárias sobre a probabilidade resultam de crenças e experiências cotidianas (Fischbein,1987), e os equívocos referentes à compreensão probabilística afetam as suas decisões acerca de importantes situações, como exames médicos, vereditos de júri, investimentos, avaliações, seguros, entre outras. Para que estas intuições se desenvolvam e as compreensões iniciais (que nem sempre estão em consonância com o conhecimento formal) se ampliem, é necessário que haja intervenção por meio de ensino. Ou seja, há conhecimentos de natureza probabilística que só serão consolidados por meio da ação pedagógica da escola, tendo como ponto de partida as intuições iniciais das crianças, sendo necessário compreendêlas. Justifica-se, assim, a importância que a compreensão probabilística tem adquirido na Educação Matemática, sendo essenciais os primeiros contatos dos estudantes com conceitos probabilísticos, e para um melhor desenvolvimento devem se iniciar nos primeiros anos de escolaridade.

Considerando este contexto e as mudanças curriculares com abertura para favorecer o estudo da probabilidade nos anos iniciais, diversos autores (Bryant \& Nunes, 2012; Cañizares, Batanero, Serrano \& Ortiz, 2003) defendem a realização de estudos com foco em crenças intuitivas, conhecimentos prévios e compreensão probabilística de crianças sobre justiça em jogos, como forma de apoiar a etapa seguinte da realização de propostas de ensino efetivas que promovam ou ampliem as suas aprendizagens. Contudo, ainda é escassa a investigação focada nas crenças de crianças sobre justiça em jogos, em articulação com a compreensão probabilística, iluminando como compreendem e constroem os conceitos relativos ao tema, quais as dificuldades cognitivas que enfrentam e possíveis formas de minimizá-las.

No Brasil, a Base Nacional Comum Curricular [BNCC] (Brasil, 2017) salienta o desenvolvimento de habilidades de natureza probabilística desde os primeiros anos do Ensino Fundamental, para crianças a partir de 6 anos de idade. Contudo, o ensino da probabilidade tem sido negligenciado, especialmente pelas escolhas feitas pelos professores que apresentam fragilidade na compreensão do tema (Campos \& Pietropaolo, 2013, Pinheiro, Silva \& Pietropaolo, 2019). Em Portugal, diferentemente do Brasil, as Aprendizagens Essenciais [AE] do Ensino Básico (Ministério da Educação, 2018) estabelecem a introdução de conteúdos relativos à Probabilidade apenas no $7 .^{\circ}$ ano, não estando previsto o seu ensino nos anos iniciais (1..$^{\circ}$ ao $5 .^{\circ}$ ano). A realização deste estudo em países como o Brasil e Portugal, atendendo à especificidade dos seus contextos, é particularmente relevante para ilustrar efeitos de tradições educacionais em aprendizagens específicas sobre elementos que dão sustentação à probabilidade, e que são foco deste estudo, em ambos os países. A identificação de compreensão acerca de elementos probabilísticos por parte de crianças brasileiras e portuguesas em relação à justiça em jogos, pode contribuir para reforçar a necessidade de práticas de ensino que atendam a conceitos probabilísticos, facilitando a consolidação do seu conhecimento e o desenvolvimento de habilidades necessários à vivência da cidadania plena num mundo em constante mudança.

A relação entre jogo, sorte, justiça e influência dos deuses tem se mantido no imaginário das pessoas desde tempos remotos (Bennett, 2003) e fazem parte das suas crenças e intuições. Mas, segundo Bryant e Nunes (2012), a compreensão da aleatoriedade (com foco em independência de eventos) é um elemento necessário para garantir a justiça em jogos, e que está articulado com outros elementos fundamentais da compreensão probabilística, referidos como "demandas cognitivas", que o presente artigo também busca discutir em termos da sua relação com a justiça, em contextos de jogos: espaço amostral (com foco na análise de eventos equiprováveis e não equiprováveis); e comparação de probabilidades (com foco no raciocínio proporcional).

Objetiva-se assim, com esta pesquisa, analisar as compreensões de crianças brasileiras e portuguesas acerca de justiça em jogos, considerando demandas cognitivas da probabilidade referentes à aleatoriedade, ao espaço amostral e à comparação de probabilidades. As questões que norteiam esta pesquisa são: i) de que forma a compreensão de elementos da aleatoriedade, do espaço amostral e da comparação de probabilidades possibilitam que as crianças avaliem a justiça ou injustiça dos jogos? ii) que diferenças se evidenciam nas compreensões de crianças brasileiras e portuguesas acerca da justiça em jogos, considerando demandas cognitivas da probabilidade?

\section{Aportes Teóricos}

\section{- Demandas cognitivas da probabilidade}

Bryant \& Nunes (2102) julgam a probabilidade um conceito complexo que envolve diversos elementos referidos como "demandas cognitivas". Assim sendo, para ampla compreensão da probabilidade é necessário o desenvolvimento de quatro demandas cognitivas que envolvem:

1 - Compreensão da aleatoriedade - entender a natureza, as consequências e o uso da aleatoriedade no cotidiano;

2 - Formação e categorização do espaço amostral necessidade de reconhecer os elementos que envolvem os diversos eventos do espaço amostral;

3 - Comparação e quantificação de probabilidades compreender que a probabilidade é uma quantidade baseada em proporções e a solução baseia-se, quase sempre, em cálculos ou relações proporcionais.

4 - Entendimento de correlações - refere-se a uma associação entre eventos. 
Para esses autores, essas demandas cognitivas se relacionam entre si e são fundamentais para resolver problemas probabilísticos. Assim, para comparar probabilidades, por exemplo, é necessário compreender a presença e propriedades da aleatoriedade, compreender os eventos que compõem o espaço amostral, e estabelecer uma relação proporcional para quantificar e comparar as probabilidades. As correlações, que se configuram na relação entre eventos, necessita da compreensão das demais demandas e nem sempre é necessária nas questões probabilísticas (Bryant \& Nunes, 2012), razão pela qual não a exploramos em nosso estudo.

A BNCC (Brasil, 2017) evidencia a exploração de aspectos da probabilidade desde o $1 .^{\circ}$ ano do Ensino Fundamental e apresenta consonância com as demandas cognitivas de Bryant e Nunes (2012), enfatizando no $1 .^{\circ}$ e $2 .^{\circ}$ anos o desenvolvimento de habilidades voltadas à compreensão da aleatoriedade, no $3 .^{\circ}$ ano o estudo do espaço amostral e no $4 .^{\circ}$ e $5 .^{\circ}$ anos o foco em quantificação e comparação de probabilidades. Assim como nesse estudo, a quarta demanda - correlações - também não é explorada na BNCC.

A independência de eventos é um importante aspecto da aleatoriedade. Bryant e Nunes (2012), assim como Bennett (2003), pontuam que a aleatoriedade é uma boa forma de garantir a justiça nos jogos. A incerteza dos resultados nos jogos de azar pode ser vista como um indicativo de que o jogo é justo, pois com resultados aleatórios e regras justas, as chances $^{1}$ serão iguais para os jogadores. Assim, ao lançar um dado ou uma moeda, embora possa se prever a probabilidade de resultados, não se pode ter certeza do que sairá no primeiro ensaio ou nos demais, pois a aleatoriedade se caracteriza pela incerteza e não tem compromisso com resultados que antecederam ou que irão suceder.

As pessoas têm dificuldades de perceber a independência de eventos e tendem a crer que uma sequência é aleatória se parecer desordenada ou sem padrão discernível (Pratt, 2000; Bryant \& Nunes, 2012). Por exemplo, creem equivocadamente que é mais provável sair a sequência 5, 3, 1, 4, 2 no lançamento de um dado do que a sequência 5, 5, 5, 5, 5. Esta é uma crença equivocada sobre sequências aleatórias e, neste ponto, se relacionam com a compreensão do espaço amostral. Se as pessoas pudessem compreender todas as possibilidades que podem sair em uma sequência de seis números num determinado sorteio (com reposição), seria possível constatar que cada uma das sequências particulares (desordenadas ou não) seriam equiprováveis.

Em relação ao espaço amostral, Bryant e Nunes (2012) consideram que conhecê-lo é um passo essencial para resolver problemas de probabilidade, pois esses problemas levam em conta um conjunto de possíveis, mas incertos, resultados que ocorrem de forma aleatória. Para compreender amplamente o espaço amostral, se faz necessário o uso do raciocínio combinatório, pois é importante pensar nas combinações possíveis de todos os resultados do evento e relacioná-lo com o espaço amostral (Bryant \& Nunes, 2012).

No entanto, não basta apenas inventariar as possibilidades do espaço amostral, pois nem sempre os eventos são equiprováveis. É necessário relacionar a quantidade de elementos do evento ao conjunto completo de elementos que é o espaço amostral, e esta é uma relação de proporcionalidade (Batanero \& Diaz, 2007). Sair a sequência 'cara-cara-cara' no lançamento de três moedas tem a mesma probabilidade de sair a sequência 'cara-coroa-coroa', ou seja $1 / 8$. No entanto, 'sair faces iguais' (2 em 8) e 'sair faces diferentes' (6 em 8) não são eventos equiprováveis. A observância dessas diferenças (eventos equiprováveis e não-equiprováveis) nem sempre é percebida, adotando-se um 'viés da equiprobabilidade' ao considerar que os eventos de forma geral, têm mesmas chances de ocorrerem.

Para quantificar e comparar probabilidades é exigido que se estabeleça uma relação proporcional e o uso do raciocínio proporcional se configura numa dificuldade para crianças e adultos (Bryant \& Nunes, 2012; Cañizares et al., 2003). E comparar probabilidades de espaços amostrais distintos se configura numa dificuldade ainda maior em função do baixo desenvolvimento do raciocínio proporcional (Bryant \& Nunes, 2012). Quando se compara probabilidades, considerando o mesmo espaço amostral, não é explicitamente necessário estabelecer a relação proporcional. No entanto, em diferentes espaços amostrais, a relação proporcional é imprescindível. Para comparar as probabilidades, por exemplo, de retirar aleatoriamente bola vermelha em caixas que possuam 2 bolas vermelhas e 3 pretas (Caixa A) e 3 bolas vermelhas e 6 pretas (Caixa B), não é suficiente analisar apenas as quantidades de bolas vermelhas em cada caixa. É necessário estabelecer a comparação proporcional entre as razões $2 / 3$ e 3/6. Bryant e Nunes (2012) ilustram a dificuldade dos estudantes de 15 anos que realizaram o PISA (Programme for International Student Assessment) e responderam questão semelhante. Dos estudantes europeus, $73 \%$ não conseguiram analisar $e$ responder corretamente à questão, possivelmente em função de não utilizar a relação proporcional.

\section{- Crenças sobre justiça em jogos}

Watson e Moritz (2003) propuseram níveis de crenças observados em crianças e adolescentes ao avaliarem a justiça no lançamento de dados, que foram categorizados considerando os tipos de respostas dos alunos, em conformidade com o Quadro 1. 
Quadro 1 - Níveis de crença sobre justiça no lançamento de dados

\begin{tabular}{|c|c|l|}
\hline Nível & Descrição & \multicolumn{1}{|c|}{ Explicação } \\
\hline Icônico & Injusto & $\begin{array}{l}\text { Crenças de que os dados } \\
\text { são injustos, muitas vezes } \\
\text { envolvendo experiências } \\
\text { pessoais sobre jogos. }\end{array}$ \\
\hline Uniestrutural & Justo & $\begin{array}{l}\text { Crença teórica em justiça ou } \\
\text { igualdade de chances em uma } \\
\text { forma proposicional; qualquer } \\
\text { referência à experiência } \\
\text { é secundária à principal } \\
\text { conclusão de justiça. }\end{array}$ \\
\hline Multiestrutural & $\begin{array}{l}\text { Justo } \\
\text { qualificado }\end{array}$ & $\begin{array}{l}\text { Crença que os dados são } \\
\text { justos, sujeitos à condição } \\
\text { de rolamento de uma técnica } \\
\text { qualificada de rolamento ou à } \\
\text { condição física da fabricação } \\
\text { dos dados, considerando a } \\
\text { forma e o “peso". }\end{array}$ \\
\hline Relacional & $\begin{array}{l}\text { Variação } \\
\text { de curto } \\
\text { prazo }\end{array}$ & $\begin{array}{l}\text { Crença que os resultados são } \\
\text { justos a longo prazo, mas que } \\
\text { os resultados de curto prazo } \\
\text { ou a lembrança seletiva da } \\
\text { experiência podem sugerir o } \\
\text { contrário. }\end{array}$ \\
\hline
\end{tabular}

Fonte: Watson \& Moritz (2003, p.280)

Em relação às estratégias dos estudantes para avaliar os dados em justo, ou não, os pesquisadores associaram a cada nível uma descrição assim caracterizada:

a. Nível Icônico (estratégia idiossincrática) - Incorporação de crenças intuitivas (por exemplo, antropomorfismo ${ }^{2}$ ), muitas vezes sobre números específicos (sorte) e, portanto, envolvimento com dados de maneira idiossincrática. b. Nível Uniestrutural (estratégia não testável) - Afirmação de que os dados são justos; nenhum teste é necessário.

c. Nível Multiestrutural (estratégia observacional) Observação de características físicas, por exemplo, se cada resultado possível é representado em apenas uma face; ou simetria em termos de medição de peso ou forma, ou técnica de rolamento específica; ou alguns ensaios não sistemáticos para apoiar um argumento, mas sem técnica de registro sistemático e resultados não utilizados para tirar conclusões. d. Nível Relacional (estratégia empírica)-Ensaios sistemáticos dos dados, registro de resultados e comparação das respetivas frequências, a serem considerados se a sua distribuição for uniforme. Pequenos ensaios com amostras incluem menos de 18 lançamentos de cada dado, e os resultados são, por vezes, registrados numa sequência. Ensaios de amostra grande já incluem mais de 18 lançamentos, com registro de resultados e resumos das frequências de cada um.

\section{- Construtos do pensamento probabilístico}

Um estudo de Jones, Langrall, Thornton e Mogrill (1997), envolvendo crianças, culminou na criação de um quadro de análise contemplando quatro construtos básicos para identificar o desenvolvimento do pensamento probabilístico: espaço amostral, probabilidade de um evento, comparação de probabilidades e probabilidade condicional ${ }^{3}$. Para cada um desses construtos, foram relacionados distintos níveis de compreensão que refletem um continuo que se inicia no nível mais elementar denominado Subjetivo e se amplia para níveis posteriores como o Transitório e o Quantitativo Informal, culminando no nível mais elevado, o Numérico, como especificados no Quadro 2.

Quadro 2 - Níveis dos construtos do pensamento probabilístico

\begin{tabular}{|c|c|c|c|c|}
\hline Construto & $\begin{array}{c}\text { Nível 1 } \\
\text { Subjetivo }\end{array}$ & $\begin{array}{c}\text { Nível } 2 \\
\text { Transitório } \\
\end{array}$ & $\begin{array}{c}\text { Nível 3 } \\
\text { Quantitativo Informal } \\
\end{array}$ & $\begin{array}{c}\text { Nível } 4 \\
\text { Numérico } \\
\end{array}$ \\
\hline 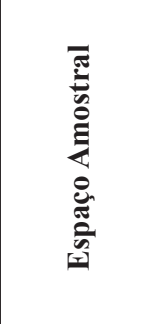 & $\begin{array}{l}\text { Lista um conjunto } \\
\text { incompleto de } \\
\text { resultados para um } \\
\text { experimento de um } \\
\text { estágio }{ }^{4}\end{array}$ & $\begin{array}{l}\text {-Lista um conjunto } \\
\text { completo de resultados } \\
\text { para um experimento de } \\
\text { um estágio } \\
\text {-Lista os resultados } \\
\text { do experimento de } \\
\text { dois estágios de uma } \\
\text { maneira limitada e não } \\
\text { sistemática }\end{array}$ & $\begin{array}{l}\text {-Adapta e aplica parcialmente uma } \\
\text { estratégia genérica para fazer uma lista } \\
\text { completa de resultados para um caso de } \\
\text { dois estágios }\end{array}$ & 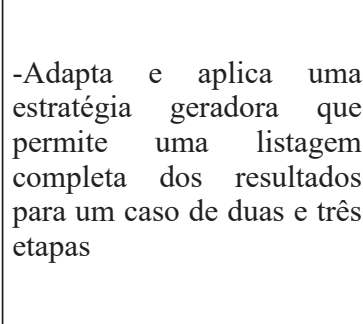 \\
\hline 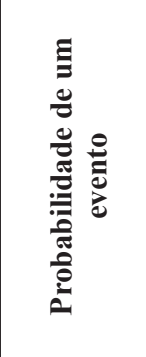 & $\begin{array}{l}\text {-Prevê o evento mais } \\
\text { / menos provável com } \\
\text { base em julgamentos } \\
\text { subjetivos } \\
\text {-Distingue eventos } \\
\text { certos, possíveis e } \\
\text { impossíveis de forma } \\
\text { limitada }\end{array}$ & $\begin{array}{l}\text { - Prevê o evento mais } \\
\text { / menos provável com } \\
\text { base em julgamentos } \\
\text { quantitativos, mas } \\
\text { pode reverter para } \\
\text { julgamentos subjetivos } \\
\text { - Distingue eventos } \\
\text { certos, possíveis e } \\
\text { impossíveis com } \\
\text { parâmetros razoáveis. }\end{array}$ & $\begin{array}{l}\text { - Prevê o evento mais / menos provável } \\
\text { com base em julgamentos quantitativos, } \\
\text { incluindo situações que envolvem } \\
\text { resultados não-contínuos } \\
\text {-Usa números informalmente para } \\
\text { comparar probabilidades } \\
\text {-Distingue eventos certos, possíveis } \\
\text { e impossíveis e justifica as escolhas } \\
\text { quantitativamente. }\end{array}$ & $\begin{array}{l}\text {-Prevê eventos mais / } \\
\text { menos prováveis para } \\
\text { experimentos de estágio } \\
\text { único } \\
\text {-Atribui uma probabilidade } \\
\text { numérica a um evento (pode } \\
\text { ser uma probabilidade } \\
\text { real ou uma forma de } \\
\text { probabilidade) }\end{array}$ \\
\hline
\end{tabular}

2 Diz-se da atribuição de características humanas a objetos e seres inanimados. No contexto específico, atribui-se algum poder ou vontade aos dados que podem, de alguma forma, influenciar os resultados.

3 Diz respeito a ensaios ou eventos que sofrem a influência de outros, ou seja, os resultados futuros de determinados eventos estão condicionados a resultados anteriores.

4 Por exemplo, o lançamento de um dado. E de dois estágios, o lançamento de dois dados. 


\begin{tabular}{|c|c|c|c|c|}
\hline Construto & $\begin{array}{c}\text { Nível 1 } \\
\text { Subjetivo }\end{array}$ & $\begin{array}{c}\text { Nível 2 } \\
\text { Transitório }\end{array}$ & $\begin{array}{c}\text { Nível 3 } \\
\text { Quantitativo Informal }\end{array}$ & $\begin{array}{c}\text { Nível } 4 \\
\text { Numérico }\end{array}$ \\
\hline 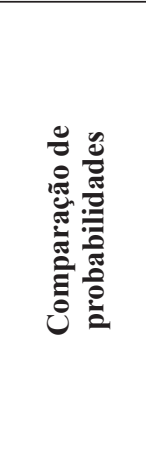 & $\begin{array}{l}\text {-Compara a } \\
\text { probabilidade de } \\
\text { um evento em dois } \\
\text { espaços amostrais } \\
\text { diferentes, geralmente } \\
\text { com base em vários } \\
\text { julgamentos subjetivos } \\
\text { ou numéricos. } \\
\text { - Não consegue } \\
\text { distinguir situações de } \\
\text { probabilidade justas de } \\
\text { situações injustas }\end{array}$ & \begin{tabular}{|lr}
-Faz comparação de \\
probabilidades baseado \\
em ralgamentos \\
quantitativos (pode não \\
quantificar corretamente \\
e pode haver limitação \\
quando elementos \\
não-contínuos estão \\
envolvidos) \\
-Começa a distinguir \\
situações r de \\
probabilidade justas de \\
situações injustas
\end{tabular} & $\begin{array}{l}\text {-Faz comparação de probabilidades } \\
\text { baseado em julgamentos quantitativos } \\
\text { consistentes } \\
\text {-Justifica, validando com raciocínio } \\
\text { quantitativo, mas pode haver limitação } \\
\text { quando eventos não-contínuos estão } \\
\text { envolvidos } \\
\text { - Distingue situações de probabilidade } \\
\text { justas de situaçoes injustas geralmente } \\
\text { baseado em validação de raciocínio } \\
\text { numérico }\end{array}$ & $\begin{array}{l}\text {-Atribui uma probabilidade } \\
\text { numérica para mensurar } \\
\text { uma comparação } \\
\text {-Incorpora resultados } \\
\text { contínuos e não- } \\
\text { contínuos determinando } \\
\text { probabilidades }\end{array}$ \\
\hline 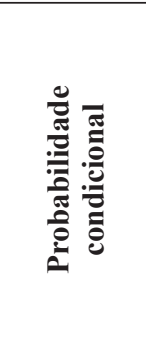 & $\begin{array}{l}\text {-Seguindo um } \\
\text { determinado resultado, } \\
\text { prevê consistentemente } \\
\text { que ocorrerá da } \\
\text { próxima vez ou, } \\
\text { alternativamente, que } \\
\text { não ocorreránovamente } \\
\text { (overgeneralizes) }\end{array}$ & $\begin{array}{l}\text { - Começa a reconhecer } \\
\text { que a probabilidade de } \\
\text { um evento muda em } \\
\text { uma situação de não } \\
\text { reposição } \\
\text {-Pode reconhecer } \\
\text { quando eventos certos } \\
\text { e impossíveis surgirão } \\
\text { em situações de não- } \\
\text { reposição }\end{array}$ & $\begin{array}{l}\text {-Pode determinar a mudança da medida } \\
\text { da probabilidade em situações de não } \\
\text { reposição } \\
\text {-Reconhece a probabilidade de um } \\
\text { evento muda em situações de não- } \\
\text { substituição }\end{array}$ & 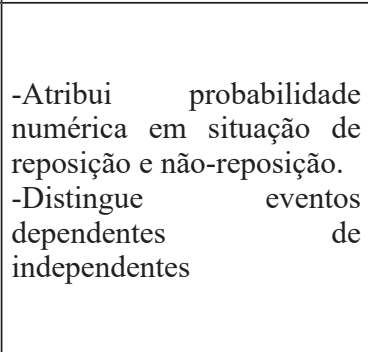 \\
\hline
\end{tabular}

Fonte: Jones et al. (1997, p.103).

Posteriormente, Jones (2006) revisitou o estudo de Jones et al. (1997) e propôs uma ampliação do construto 'probabilidade condicional' para incluir independência de eventos. Assim, o pensamento relativo ao i) Nível Subjetivo considera que eventos consecutivos são sempre relacionados, possui crença difusa de que pode controlar o resultado de um evento, usa raciocínio subjetivo que impede qualquer foco significativo em independência e exibe confiança indevida na previsão de resultados sucessivos; ii) Nível Transitório Mostra algum reconhecimento sobre eventos consecutivos se estão relacionados, ou não, usa frequentemente uma estratégia de "representatividade", seja uma orientação de recência positiva ou negativa ${ }^{5}$, reverte para o raciocínio subjetivo; iii) Nível Quantitativo informal - reconhece quando o resultado do primeiro evento influencia, ou não, o resultado do segundo evento, em situações de reposição, vê o espaço amostral como restaurado, diferencia, embora imprecisamente, eventos independentes e dependentes em "com" e "sem" situações de reposição e reverte para a representatividade; iv) Nível Numérico - distingue eventos dependentes e independentes em situações de reposição e não-reposição, usando probabilidades numéricas para justificar seu raciocínio, observa os resultados de ensaios sucessivos, mas rejeita uma estratégia de representatividade e reluta ou recusa previsões de resultados quando os eventos são igualmente prováveis.

Os diversos níveis consideram uma gradação na compreensão dos construtos por parte das crianças. Assim, o Nível Subjetivo é o mais elementar, contemplando crianças que possuem uma perspectiva estreita em relação às situações probabilísticas, caracterizado pela dificuldade de reconhecer fenômenos aleatórios e basear seus julgamentos em crenças subjetivas. As crianças do Nível Transitório apresentam uma compreensão um pouco mais consistente de fenômenos aleatórios e do espaço amostral, mas ainda estão em processo de transição e podem reverter ao Nível Subjetivo. No Nível Quantitativo Informal, as crianças começam a criar uma estratégia sistematizada para elencar elementos do espaço amostral de eventos de dois estágios, por exemplo. No Nível mais elevado, o Numérico, as crianças reconhecem probabilidade condicional e compreendem eventos independentes, além de criarem estratégias coerentes para listar elementos de eventos de dois ou mais estágios.

\section{Contexto e Metodologia do Estudo}

O estudo faz parte de uma pesquisa de doutoramento mais alargada e foi realizado por meio de uma entrevista clínica baseada no método clínico piagetiano (Carraher, 1998), aplicada individualmente a todos os participantes voluntários, num ambiente calmo e silencioso. A entrevista, realizada por este método e baseada em questões orientadoras, foi audiogravada e transcrita, permitindo analisar as respostas das crianças participantes que evidenciam o seu pensamento e crenças acerca de determinadas situações propostas para resolução. No Brasil, participaram 15 crianças de escola pública do município do Cabo de Santo Agostinho (PE) que residiam em bairro periférico e pobre da cidade. Em Portugal, fizeram parte do estudo 15 crianças de escola pública de bairro de classe média de Lisboa. A entrevista foi realizada na escola e conduzida pela pesquisadora, primeira autora do

5 Recência positiva diz respeito à crença de que resultados que aconteceram repetidas vezes anteriormente, tendem a se repetir novamente e recência negativa se apoia no contrário: julgar que determinado resultado não ocorrerá, uma vez que já aconteceu diversas vezes antes. 
texto. Em ambos os grupos, as crianças cursavam o $5^{\circ}$ ano, com média de idade de 11 anos e não tiveram acesso formal a conteúdos de natureza probabilística. Como referido, em Portugal, o tema não faz parte do currículo do $5^{\circ}$ ano e no Brasil, em conformidade com Campos \& Pietropaolo (2013), as fragilidades dos professores parecem influenciar a escassez da probabilidade nas salas de aula da Educação Básica.

Nas entrevistas, seis jogos (Quadro 3), três justos e três injustos, foram explorados pelas crianças seguindo a ordem apresentada, que tiveram a oportunidade de manusear os jogos e experienciar algumas jogadas para se familiarizarem com os artefatos e regras estabelecidas em cada um. Em seguida, avaliaram se o jogo era justo, ou não, a partir da comparação de probabilidades de vencer dos jogadores envolvidos nos contextos apresentados. Na perspectiva discutida nesse texto, consideramos jogo justo ${ }^{6}$ aquele em que todos os jogadores possuem a mesma probabilidade de vencer (Borovicnik, 2016; Bennett, 2003) e para tal, a aleatoriedade precisa ser garantida, os aleatorizadores precisam ser honestos e as regras justas.

Quadro 3 - Tarefas das entrevistas: Jogos justos e injustos com foco probabilístico

Continua...

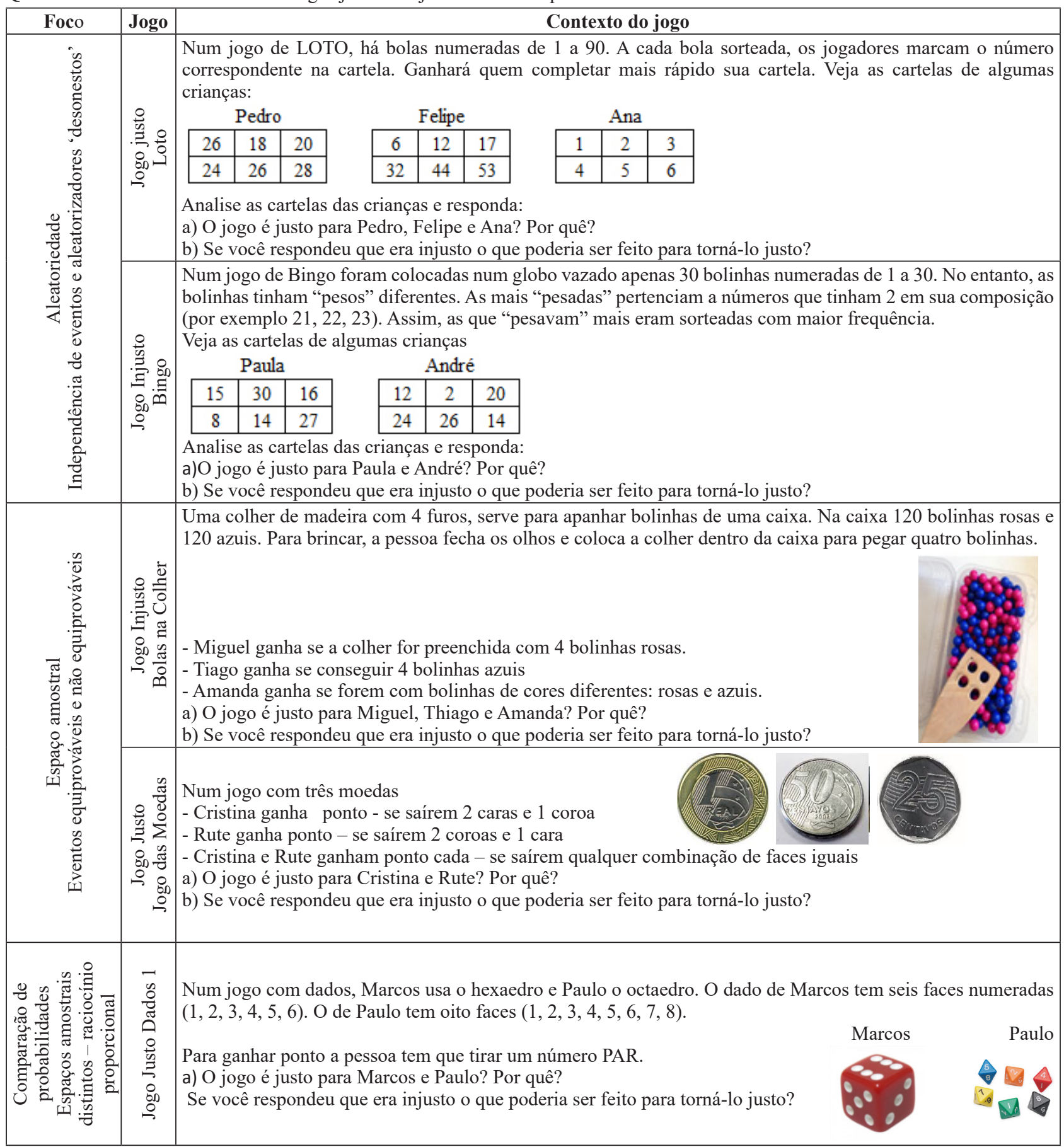

6 Segundo Bennett (2003) uma outra modalidade de jogo justo se traduz naquela em que há probabilidades diferentes para os jogadores vencerem, mas a premiação é inversamente proporcional. No entanto, esse não é um foco de nosso estudo. 


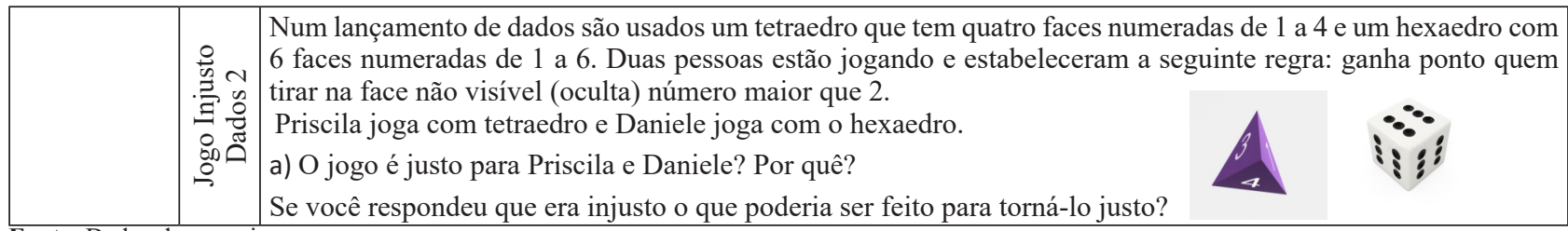

Nos jogos, consideramos alguns elementos da probabilidade que estão relacionados às demandas cognitivas (Bryant \& Nunes, 2012) e apresentam aproximação com os construtos do pensamento probabilístico (Jones et al., 1997; Jones, 2006). Assim, no que concerne à aleatoriedade, o foco de discussão é centrado na independência de eventos, mas também se observou a influência de aleatorizadores desonestos; para explorar o espaço amostral, usamos jogos que consideram eventos equiprováveis e não-equiprováveis e exploramos espaço amostrais distintos para comparar probabilidades a fim de verificar o uso (ou não) do raciocínio proporcional.

Em cada um dos jogos, as crianças precisaram comparar probabilidades, no entanto, o foco em cada par de jogos é específico, em função do que se pretende investigar, em conformidade com o Quadro 3. No entanto, independente do foco probabilístico explorado, os jogos apresentados exigem uma interconexão das compreensões das demandas cognitivas. Dessa forma, ao comparar probabilidades é necessário que se compreenda que se trata de um experimento que é aleatório e que é necessário conhecer e explorar o espaço amostral para estabelecer as comparações, como apontado por Bryant \& Nunes (2012).

A análise dos dados, de natureza descritiva e interpretativa (Wolcott, 2009), tem por base as respostas dos participantes obtidas na entrevista clínica relativas à justiça do jogos, com foco nos elementos da compreensão da probabilidade referidos por Bryant \&Nunes (2012) e os níveis de pensamento probabilístico estabelecidos por Jones et al. (1997) e Jones (2006) para essa compreensão. Esta análise considera não apenas o julgamento (correto ou incorreto) sobre a justiça ou injustiça presente nos jogos, mas, sobretudo as justificativas que apoiam as escolhas dos participantes, pois elas apontam para compreensões ou equívocos acerca dos elementos explorados no estudo. Assim, as respostas das crianças são classificadas como corretas quando justificam corretamente que o jogo foi justo ou injusto e apresentam argumentos que são coerentes do ponto de vista conceitual.

Na secção seguinte apresentamos os resultados da análise, exemplificada com excertos das respostas das crianças participantes que contemplam e evidenciam a diversidade obtida nas entrevistas. Para garantir o seu anonimato, as crianças brasileiras serão identificadas com os códigos $\mathrm{CB} 1, \mathrm{CB} 2 \ldots \mathrm{CB} 15$, considerando a ordem em que foram entrevistadas, assim como as crianças portuguesas que foram identificadas por CP1, CP2...CP15.

\section{Resultados e Discussão}

O Quadro 4 apresenta os resultados das respostas das crianças que avaliaram corretamente a justiça dos jogos, considerando o seu julgamento e os argumentos apresentados, que apontam para a compreensão dos elementos probabilísticos específicos discutidos em cada jogo.

Quadro 4 - Respostas corretas das crianças (15 de cada país), por jogo e foco probabilístico

\begin{tabular}{|c|c|c|c|}
\hline \multirow[b]{2}{*}{ Foco do jogo } & \multirow[b]{2}{*}{ Tipos de jogos } & \multicolumn{2}{|c|}{ Respostas corretas } \\
\hline & & $\begin{array}{c}\text { Crianças } \\
\text { Brasileiras }\end{array}$ & $\begin{array}{c}\text { Crianças } \\
\text { Portuguesas }\end{array}$ \\
\hline \multirow{2}{*}{$\begin{array}{c}\text { Aleatoriedade } \\
\text { (Independência } \\
\text { de eventos) }\end{array}$} & $\begin{array}{l}\text { Jogo justo } \\
\text { Loto }\end{array}$ & 1 & 2 \\
\hline & $\begin{array}{c}\text { Jogo injusto } \\
\text { Bingo }\end{array}$ & 13 & 13 \\
\hline \multirow{2}{*}{$\begin{array}{c}\text { Espaço } \\
\text { amostral } \\
\text { (eventos } \\
\text { equiprováveis } \\
\text { e não- } \\
\text { equiprováveis) } \\
\end{array}$} & $\begin{array}{c}\text { Jogo justo } \\
\text { Moedas }\end{array}$ & 11 & 14 \\
\hline & $\begin{array}{l}\text { Jogo injusto } \\
\text { Bolas na co- } \\
\text { lher }\end{array}$ & 13 & 13 \\
\hline \multirow{2}{*}{$\begin{array}{c}\text { Comparação de } \\
\text { probabilidades } \\
\text { (espaços } \\
\text { amostrais } \\
\text { distintos - } \\
\text { raciocínio } \\
\text { proporcional) }\end{array}$} & $\begin{array}{c}\text { Jogo justo } \\
\text { Dados } 1\end{array}$ & 0 & 0 \\
\hline & $\begin{array}{c}\text { Jogo injusto } \\
\text { Dados } 2\end{array}$ & 0 & 0 \\
\hline
\end{tabular}

Fonte: Dados da pesquisa.

Em relação aos jogos que exploraram a independência de eventos, observou-se uma frágil compreensão desse elemento, especialmente na exploração do jogo LOTO (justo). Nesse jogo, das crianças que informaram que o jogo era justo, apenas uma criança brasileira (CB4) e duas portuguesas (CP12 e CP15) apresentaram argumentos que apontaram para indícios de compreensão sobre a independência de eventos, como observado nos excertos das falas a seguir: "Sim é justo, porque é uma questão de sorte, né? Acho que tem a mesma chance de ganhar porque têm todos esses números aqui (no saco), né?" (CB4); "É justo para os três. Eles têm as mesmas vantagens. Se é até o 90 aqui não há nenhum número que ultrapasse o 90, então os três têm as mesmas vantagens" (CP12); e

Sim. Porque ser número 'ao calhas"7 que tirar. Todos têm as mesmas vantagens porque os números saem 'ao calhas'. Eu escolheria qualquer uma cartela porque vai ser números 'ao 
calhas' quando tirar e pode calhar qualquer um dos números. (CP15)

Analisando as compreensões de CB4 e CP12, elas encontram-se no Nível Transitório dos construtos do pensamento probabilístico de Jones (2006) referente à independência de eventos, pois mostram algum reconhecimento de que os eventos consecutivos não estão relacionados. No entanto, CP15 está no Nível Quantitativo Informal, pois aparentemente, na ótica da criança, os ensaios não estão relacionados, por isso julga que qualquer cartela poderia ser vencedora e que não teria nenhuma preferência por nenhuma delas porque os números "caem ao calhas".

As sequências das cartelas de Pedro (16, 18, 20, 24, $26,28)$, Felipe $(6,12,17,32,44,53)$ e de Ana $(1,2,3,4$, 5 , 6) foram alvo do olhar da maioria das crianças que incorretamente consideraram o jogo injusto por acreditarem, especialmente, que sequências formadas por números que aparentam um padrão discernível teriam menos chances de serem sorteadas, como constatado no argumento da CP1 que informou que "não é justo porque Ana só tem números seguidos e os outros não têm. Felipe tem mais chances porque tem números espalhados". Outras consideraram que números maiores (ou menores) teriam maior probabilidade de saírem no sorteio, como observado na resposta da CB8: "Felipe tem mais chances de ganhar que os outros porque tem os números mais altos. Ana tem menos chance porque os números dela são muito baixos e muito dificilmente ela vai ganhar". Esse é um equívoco evidenciado por Bryant e Nunes (2012) e que coloca esses participantes no Nível Subjetivo dos construtos do pensamento probabilístico de Jones (2016) ao considerar que eventos consecutivos estão relacionados.

No jogo do BINGO (injusto), apesar de ser possível avaliar a compreensão da independência de eventos, esse fato foi eclipsado pela obviedade dos 'aleatorizadores desonestos'. Assim, as crianças focaram o olhar sobre esses aleatorizadores e a relação deles com os números das cartelas dos jogadores: Paula $(15,30,16,8,14,27)$ e André $(12,2,20,26,24$, 14). Embora a incerteza sobre os resultados se mantivesse no jogo, a injustiça de ter algumas 'bolinhas' com massa maior influenciou fortemente a análise das crianças. Assim, acertadamente, para a maioria delas, o jogo foi considerado injusto, e os argumentos apresentados repousaram sobre a probabilidade maior de sair números que em sua formação teriam o algarismo 2 - que beneficiaria André, como observado nos seguintes argumentos: "Não. Porque a de Paula só tem um número 2 e a de André tá cheio. Isso quer dizer que ele tem mais chance de ganhar porque as bolas estão mais pesadas" (CB9); e "É mais justo para o André porque ele tem todos menos o 14 que tem o número 2" (CP6).

Watson \& Moritz (2003) verificaram que há estudantes que consideram os aleatorizadores (dados) sempre justos, depois de vários experimentos, mesmo quando eles são 'desonestos'. No nosso estudo, desde o princípio foi evidenciado às crianças, nesse jogo, a 'desonestidade' dos artefatos, e esse foi um forte facilitador para que elas avaliassem corretamente a injustiça presente no jogo. Assim, constatamos que as crianças não apresentam dificuldades para avaliar justiça em jogos, se os aleatorizadores são explicitamente evidenciados como 'desonestos' ou 'viciados'.

Das crianças que se equivocaram nas respostas, CP3 evidenciou a incompreensão da independência de eventos "é justo porque tá aparecendo números diferentes (nas cartelas) uns dos outros e não tá em ordem"; CP14 e CB10 consideraram justo, mesmo evidenciando as chances desiguais dos jogadores, se apoiando unicamente na incerteza dos resultados, ao afirmarem que "É justo para um e é justo para o outro. André tem mais vantagem de ganhar porque tem mais números com 2. Mas Paula pode ganhar e André também pode" (CP14) e "Esse tem mais chance de ganhar: André (...) E essa não tem tanto. Mesmo ele tendo mais chance é um jogo justo. Ela também pode ganhar" (CB10). Já CB4 recorreu ao fato de que os números de ambas as cartelas estavam no globo e poderiam ser sorteados, não atentando para a injustiça dos aleatorizadores viciados:

é questão de sorte e tem o número até 30 e aqui não tem mais que 30 nas cartelas. Aqui tem 15, 16, 8, 14 e 27 e 30, então ele não vai pegar outras bolas que não estão. Eu acho que é justo por causa disso. E ela também tem 2 e que não passam de 30 . As chances são iguais.

Podemos dizer que crianças que pensam como CB4 estão, na análise dessa questão, num nível de crença Uniestrutural que se caracteriza por uma crença teórica na justiça, sem referência à experiência, como uma crença cega de que o jogo é justo.

Em relação aos jogos que exploram o espaço amostral, observamos que as crianças apresentaram indícios de compreensões mais substanciais no que se refere à comparação de eventos equiprováveis e não equiprováveis, mas não exatamente do espaço amostral como um todo. Possivelmente, esse resultado se deve ao fato de que nos contextos apresentados, as crianças não precisaram fazer uma lista exaustiva de todos os elementos dos eventos para poder compará-los e isso pode ter sido um facilitador para o julgamento deles.

No jogo BOLAS NA COLHER (injusto), havia 120 bolinhas azuis e 120 rosas. Assim, há 16 possibilidades de organização das bolas na colher (Figura 1), sendo 14 possibilidades em 16 de sair bolas duas cores (jogada de Amanda) e apenas uma possibilidade em 16 de sair só rosa (jogada de Miguel) ou só azul (jogada de Tiago). Para cada evento particular, os resultados são equiprováveis, ou seja, 'sair tudo rosa' ou 'sair uma rosa no canto superior direto e as demais azuis' têm as mesmas probabilidades de acontecer: 1 em 16. 
Figura 1 - Possibilidades para organização de bolas de duas cores em colher com quatro furos

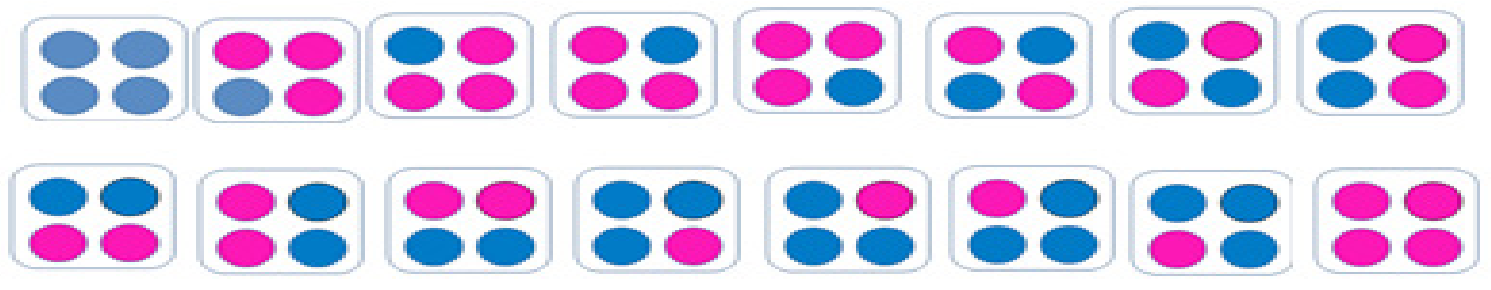

Fonte: Os autores.

No entanto, nos eventos não equiprováveis que as crianças tiveram que comparar havia um distanciamento demasiado nas probabilidades de resultados (1/16 para uma única cor e $14 / 16$ pra duas cores) e isso parece ter influenciado as respostas das crianças. Eles evidenciaram não exatamente os eventos particulares, mas, especialmente a quantidade de bolas e o fato de estarem 'misturadas'. Para eles, como as bolas estavam 'misturadas' havia muito mais chances de se obter resultados mistos (bolas azuis e rosas), como apresentado nas justificativas seguintes:

Não, porque há mais possibilidades de Amanda ganhar, porque há mais possibilidades de calhar as duas cores juntas. Estão os dois misturados na caixa, então se tirar assim, então eu acho tem mais possibilidades de calhar as duas. São 120 cada uma e na caixa já estão todos misturados. (CP12)

É quase impossível sair 4 rosas e 4 azuis. É mais fácil sair colorido (misturado). Não é justo. Amanda tem mais chance. (CB9)

Poucas crianças recorreram à explicitação dos elementos dos eventos que compunham o espaço amostral para justificar suas escolhas. CP6 recorreu à recente experiência no jogo e especificou alguns desses eventos para argumentar que:

A Amanda ganharia muito mais facilmente porque quando se tira é muito mais difícil sair da mesma cor. Pelo menos comigo, quando experimentei não saiu da mesma cor. Saíram sempre três de alguma cor com um de cor diferente ou dois de cada cor.

Implicitamente CP6 elencou os eventos "dois rosas e dois azuis", "três azuis e um rosa" e "três rosas e um azul" e concluiu que sair os eventos "tudo rosa" ou "tudo azul" seria muito mais difícil. Encontramos na sua fala indícios de compreensão sobre as possibilidades que envolvem o espaço amostral, embora, seja prematuro dizer que ele seria capaz de fazer uma lista exaustiva. Em conformidade com os construtos do pensamento probabilístico de Jones et al (1997), crianças com a compreensão semelhante a CP6 estão no nível Transitório que se caracteriza pela capacidade de listar de forma incompleta, elementos de um evento de dois estágios.

As crianças que responderam equivocadamente que o jogo seria justo apresentaram justificativas como: i) Justiça com chances diferentes - "Acho que é justo. Porque...calha uma vez na Amanda. depois em Tiago e outra vez em Miguel. Acho que Amanda tem mais chance de ganhar, pelo que eu vi quando eu joguei, sai mais azul e rosa. (CP14); ii) Chances iguais "Acho justo porque os três têm possibilidades de ganhar. As chances deles são iguais" (CB2); iii) Regras (quantidade de bolas) - "Acho que é justo porque tem a mesma quantidade de bolas, só que ele pega o total de tudo rosa e ele de tudo azuis e ela pegou misturado" (CB4).

No JOGO DAS MOEDAS (justo), os eventos são equiprováveis, ou seja, sair 'duas caras e uma coroa' é igualmente provável a sair 'duas coroas e uma cara'. Há oito resultados possíveis no lançamento de três moedas e cada um desses resultados particulares são equiprováveis (1 em 8 ). Nesse jogo as crianças também não se detiveram na análise dos elementos de cada evento, e, sim, no 'equilíbrio' que ficou aparente nos eventos analisados. Os estudos de Cañizares et al. (2004) também apontaram a ideia de equilíbrio como forma de caracterizar jogos justos. Essa visão foi largamente evidenciada e pode ser observada, por exemplo, nas justificativas de CB4: "Sim [é justo]. Porque é igual só que ao contrário. Ela [Cristina] pode pegar duas caras e uma coroa e ela [Rute]. duas coroas e uma cara" e CP12:

É justo, porque aqui é duas coroas e uma cara e aqui uma coroa e duas caras, então, acho que isso é justo. Aqui duas coroas é igual a duas caras e aqui uma coroa é igual a uma cara. Se calhar tudo igual é ponto para duas.

A sorte também foi evidenciada nas respostas das crianças, como elemento que se traduz como justo, como por exemplo, na fala de CP6: "Acaba por ficar igual e acaba por ser também uma questão de sorte" e também CB14: "é como se fosse na sorte, jogando e vendo o que a moeda vai tirar. Elas têm as mesmas possibilidades de ganhar".

Os jogos de DADOS 1 e 2 foram idealizados para investigar as compreensões dos estudantes acerca do uso do raciocínio proporcional ao comparar probabilidades de eventos que envolvem espaços amostrais distintos. Observouse, portanto, uma frágil compreensão das crianças em relação ao tema. Em ambos os jogos, não foi evidenciado o uso do raciocínio proporcional para justificar as escolhas das crianças, o que culminou numa intepretação equivocada sobre jogo justo e injusto.

As justificativas apresentadas pelas crianças, quase sempre se assentavam no número absoluto de faces totais e ou pares ou ímpares, no jogo de DADOS 1 (justo) e na quantidade de faces com números maiores ou menores que 3, no jogo de DADOS 2 (injusto). Ou seja, quase sempre, os argumentos se apoiavam numa relação comparativa entre as quantidades absolutas pertencentes a um ou outro dado, deixando-se de lado a relação proporcional. No jogo de 
DADOS 1, justificativas como as de CB1 "Não é justo porque este aqui tem mais par do que este. Paulo tem mais chance de ganhar porque tem mais número par do que Marcos" e de CP4 "O Paulo tem mais números e mais números pares então há maior probabilidade de calhar para ele o número par" deixam evidente a comparação quantitativa não proporcional realizada pela maioria dos estudantes. Estas ideias estão em consonância com o Nível Subjetivo dos construtos do pensamento probabilístico de Jones et al (1997) em que as crianças não conseguem avaliar situações justas e injustas ao compararem probabilidades de um evento em dois espaços amostrais distintos com base em julgamento subjetivos ou numéricos, mas sem levar em conta a proporcionalidade que a situação exige.

Observou-se, ainda, uma análise de natureza antropomórfica dos dados (Watson \& Moritz, 2003) que diz respeito a crenças intuitivas de que o formato dos dados tem influência sobre os resultados. Crianças que apresentam essa compreensão estão no Nível Icônico de crenças de acordo com esses estudiosos, como é o exemplo de CB13 que em sua defesa afirmou que "este dado aqui é mais difícil de cair. Este é quadrado e este daqui é diferente. Ele é mais difícil sair o par nesse (Paulo)" e o de CP9 que declarou "Outra vantagem é o formato, porque este aqui gira perfeitamente bem e este aqui não gira perfeitamente bem. Pelo que eu rodei neste (Marcos), eu acho que é mais fácil tirar ímpar"

A regra 'tirar número par' foi evidenciada por alguns participantes como uma condição de justiça. CB5 afirmou que “é justo se é para qualquer um desses tirar número par”, CP8 informou "É um jogo limpo e acho calhar número par, um ganha, se calhar número par, o outro ganha também", e CP14 argumentou "acho justo, porque os dois têm possibilidades de ganhar e porque os dois são pares. Os dois têm as mesmas vantagens para ganhar porque os dois precisam tirar números pares". Evidenciar a regra é importante, mas ela não garante que o jogo seja justo, pois outros elementos precisam ser analisados, como a garantia da aleatoriedade, a honestidade dos aleatorizadores e as chances iguais para os jogadores.

No jogo de DADOS 2, por exemplo, embora a análise da quantidade de números maiores que dois, fosse evidente, a comparação não poderia ser apenas dos valores absolutos, como observado nas justificativas de CB2 "Porque este dado aqui tem quatro números maiores e este aqui tem dois. Danielle tem mais chance de ganhar" e CP4 "Acho que tá injusto pra Priscila porque o Daniel tem muitos mais números acima de 2". A falta de análise proporcional é evidente nas falas dessas crianças. Como elas responderiam à situação se a regra fosse sair número menor que 3 no tetraedro e no hexaedro? As respostas coletadas nesse estudo sugerem, que sem análise proporcional, é possível que eles julgassem que as probabilidades seriam iguais, e, portanto, o jogo seria justo.

Em nenhum dos jogos (DADOS 1 e 2), as crianças conseguiram apresentar argumentos que apontassem indícios de compreensão e uso consciente da comparação proporcional entre os eventos. A fragilidade no uso do raciocínio proporcional se configurou como uma dificuldade extrema para esses estudantes nos contextos discutidos nesse estudo. Esse fato contribuiu para equívocos substanciais ao avaliar jogo justo ou injusto. Ademais, Bryant e Nunes (2012) alertam que o raciocínio proporcional é um entrave pedagógico que está presente não apenas em contextos da probabilidade.

Nos jogos, observou-se referência à experiência recente que as crianças tiveram no decorrer da entrevista ou a outras experiências informais, especialmente com o uso de moedas e dados., como por exemplo:

- CP14: "Acho que Amanda tem mais chance de ganhar, pelo que eu vi quando eu joguei, sai mais azul e rosa",

- CP9: "Pelo que eu rodei neste dado (hexaedro), eu acho que é mais fácil tirar ímpar",

- CB12: "Cristina tem mais chance porque a dela é cara e esta aqui é coroa. A cara sai mais"

- CB13: "Rute tem mais chance porque sempre que eu jogo assim cai mais a coroa"

Essas experiências nos jogos apontam um equívoco denominado 'heurística da representatividade', ao se julgar que os poucos ensaios realizados representam os resultados probabilísticos do jogo. Assim, concluir que sai mais cara ou mais coroa no lançamento de uma moeda, baseado em alguns ensaios experienciados, é um equívoco fundamentado na experiência que, muitas vezes pode estar associado a crenças e também à sorte.

\section{Considerações Finais}

Este estudo analisou a compreensão de crianças brasileiras e portuguesas acerca da justiça em jogos, considerando elementos essenciais à compreensão da probabilidade como a aleatoriedade, espaço amostral e comparação de probabilidades (Bryant \& Nunes, 2012).

Em resposta à primeira questão do estudo, os resultados mostram que as incompreensões acerca da independência de eventos e do raciocínio proporcional foram evidentes em ambos os grupos, o que influenciou fortemente a avaliação equivocada sobre jogo justo e injusto. A existência de aleatorizadores desonestos como condição de injustiça foi evidenciada pela maioria das crianças do estudo, que é um indicador de sua compreensão de que o uso de tais artefatos viciados produzem jogos injustos.

Avaliar a justiça em eventos equiprováveis quando as sequências dos eventos aparentam um certo ‘equilíbrio' (duas caras e uma coroa - duas coroas e uma cara), mostrou-se como característica de jogo justo aos participantes. No entanto, não é possível afirmar que o desempenho seria o mesmo se, embora os eventos fossem equiprováveis, as sequências não aparentassem um certo equilíbrio como, por exemplo, comparar as probabilidades de sair num lançamento de três moedas as sequências 'cara-cara-cara' e 'coroa-cara-coroa'.

Para comparar eventos 'não-equiprováveis' a ideia de 'misturado' (bolas azuis e rosas) foi a justificativa mais marcante para apoiar as escolhas dos estudantes 
que consideraram corretamente o jogo injusto. $\mathrm{O}$ grande distanciamento entre as probabilidades dos eventos ocorrerem pode ter tornado óbvia a injustiça da situação, mas essa é uma evidência não conclusiva que necessita de novos estudos: as crianças, de fato, percebem esse distanciamento probabilístico ou apenas consideraram que "azul e rosa é mais fácil sair porque tá tudo misturado" (CP12).

Boa parte das crianças encontram-se no Nível Subjetivo que é o mais elementar dos construtos do pensamento probabilístico de Jones et al (1997) e Jones (20016), e outras estão no Nível Transitório. Em relação aos níveis de crenças (Watson \& Moritz, 2003), as crianças ora estão no nível icônico (antropomorfismo, sorte) ou no uniestrutural (crença cega na justiça dos jogos) ou no multiestrutural (condição física dos dados).

Os resultados mostram que as crianças de ambos os países têm dificuldades em alguns elementos da probabilidade aqui discutidos, semelhantemente a outros estudos envolvendo crianças (Bryant \& Nunes, 2012; Cañizares et al, 2003). No entanto, este estudo dá uma perspectiva mais alargada sobre a compreensão ao considerar que elementos da probabilidade influenciam a análise e compreensão de jogos justos ou não.

No que concerne à segunda questão, considerando o desempenho de crianças brasileiras e portuguesas, de uma forma geral, os resultados apontaram para compreensão muito semelhante dos elementos probabilísticos explorados nesse estudo. Em face das fragilidades e potencialidades que foram verificadas, tanto em crianças brasileiras como em crianças portuguesas, não é surpreendente não se terem verificado diferenças substanciais em ambos os grupos estudados. A linguagem foi o que apresentou algum distanciamento entre crianças brasileiras e portuguesas. As expressões mais utilizadas nas justificativas por ambos os grupos foi 'chance', com maior destaque dado pelas crianças brasileiras que usaram mais fortemente os termos 'sorte', 'possibilidade' e 'possível', embora também utilizadas por algumas crianças portuguesas. Já os termos 'provável' e 'probabilidade' foram usados somente por crianças portuguesas. Como não se observou distanciamento entre as compreensões acerca dos elementos probabilísticos aqui discutidos, deduz-se que a linguagem utilizada pelas crianças tenha origem cultural, do universo em que convivem, compondo o vocabulário das comunidades em que estão inseridas.

Por fim, independentemente das experiências escolares das crianças e das diferenças curriculares em ambos os países, constatamos que a compreensão sobre elementos que contemplam demandas cognitivas da probabilidade (aleatoriedade, espaço amostral, quantificação e comparação de probabilidades) influencia a avaliação de crianças sobre a justiça em jogos de azar. Isso mostra a necessidade de serem viabilizadas propostas de ensino para melhorar a capacidade dos estudantes relativa à compreensão probabilística, tomando como base suas crenças intuitivas e conhecimentos prévios sobre justiça em jogos, em concordância com alguns autores
(Bryant \& Nunes, 2012; Cañizares et al., 2003; Fischbein, 1987), especialmente acerca da independência de eventos e do raciocínio proporcional.

Deste estudo podemos retirar algumas implicações para o ensino, reforçando primeiramente a importância do uso de jogos que pode ser usado como um rico contexto para o redimensionamento das compreensões probabilísticas das crianças e a necessidade de explorar elementos envolvendo demandas cognitivas da probabilidade desde os anos iniciais, como explorado no currículo brasileiro e necessário ainda no currículo português (Brasil, 2017).

É também pertinente a realização de futura investigação que aborde como estas sugestões e a compreensão do raciocínio combinatório na análise do espaço amostral relacionando à justiça em jogos, que não foi conclusivo nesta pesquisa, podem apoiar o desenvolvimento da compreensão dos alunos sobre a probabilidade.

\section{Referências}

Batanero C., Chernoff E. J., Engel J., Lee, H. S., \& Sánchez E. (2016). Research on teaching and learning probability. ICME-13 topical surveys. Cham: Springer. doi: 10.1007/9783-319-31625-3

Batanero, C., Díaz, C. (2007). Meaning and understanding of mathematics. The case of probability In J. P. Van Bendegen \& K. François (Eds.), Philosophical Dimensions in Mathematics Education (pp. 107-127). New York, NY: Springer. doi: 10.1007/978-0-387-71575-9_6

Bennett, D. J. (2003). Aleatoriedade. São Paulo: Martins Fontes.

Borovcnik, M. \& Kapadia, R. (2010). Research and developments in probability education internationally. In M. Joubert \& P. Andrews (Eds.), Proceedings of the British Congress for Mathematics Education (pp. 41-48). Disponível em: www. bsrlm.org.uk/IPs/ip30-1/BSRLM-IP-30-1-06.pdf4

Borovenik, M. (2016). Pensamento probabilístico e alfabetização em probabilidade no contexto do risco. Educação Matemática Pesquisa, 18 (3), 1491-1516.

Brasil (2017). Base Nacional Comum Curricular [BNCC]. Brasília: Ministério da Educação. Secretaria da Educação Básica.

Brasil. Ministério de Educação (2013). Programa e metas curriculares de matemática no ensino básico. Ministério da Educação e Ciência: Lisboa. Disponível em: https://www. dge.mec.pt/sites/default/files/Basico/Metas/Matematica/ programa_matematica_basico.pdf

Bryant, P. \& Nunes, T. (2012). Children's understanding of probability: a literature review. Nuffield Foundation. Disponível em: http://www.nuffieldfoundation.org/sites/ default/files/files/Nuffield_CuP_FULL_REPORTv_FINAL. pdf

Campos, T. M. \& Pietropaolo, R. C. (2013). Um estudo sobre os conhecimentos necessários ao professor para ensinar noções concernentes à probabilidade nos anos iniciais. In R. Borba, \& C. Monteiro (Orgs.), Processos de Ensino e Aprendizagem em Educação Matemática (pp. 55-91). Recife: UFPE.

Cañizares, M. J., Batanero, C., Serrano, L., \& Ortiz, J. J. (2003). Children's understanding of fair games. Proceedings of the 3rd Conference of the European Society for Research in Mathematics Education. Bellaria, Italy, Feb. 28 - March 3, 
2003. Disponível em: http://www.mathematik.uni-dortmund. de/ erme/CERME3/tableofcontents_cerme3.php

Carraher, T. N. (1998). O Método Clínico Usando os Exames de Piaget ( $5^{\mathrm{a}}$ ed.). São Paulo: Cortez.

Fischbein, E. (1987). Intuition in science and mathematics: an educational approach. Dordrecht, The Netherlands: D. Reidel.

Franklin, C., Kader, G., Mewborn, D., Moreno, J., Peck, R., Perry, M., \& Schaeffer, R. (2007). Guidelines for assessment and instruction in statistics education report: a pre-k-12 curriculum framework. Alexandria, VA: American Statistical Association.

Gal, I. (2004). Towards 'probability literacy' for all citizens. In G. Jones (Ed.), Exploring Probability in School: Challenges for Teaching and Learning (pp. 43-71). Kluwer: Academic Publishers. doi: 10.1007/0-387-24530-8_3

Jones, G. A. (2006). The challenges of teaching probability in school. Queensland, Australia: Griffith University. doi: $10.1007 / \mathrm{b} 105829$

Jones, G. A., Langrall, C. W., Thornton, C. A., \& Mogill, T. (1997). A framework for assessing and nurturing young children's thinking in probability. Educational Studies in Mathematics, 32(2), 101-125. doi 10.1023/A:1002981520728

Kahneman, D. \& Frederick, S. (2002). Representativeness revisited: attribute substitution in intuitive judgment. In $\mathrm{T}$. Gilovich, D. Griffin, \& D. Kahneman (Eds.), Heuristics of
Intuitive Judgment: Extensions and Applications (pp. 49-81). New York, NY: Cambridge University Press. doi: 10.1017/ CBO9780511808098.004

Ministério de Educação (2018). Aprendizagens essenciais: Matemática, $5 .^{\circ}$ ano, $2 .^{\circ}$ ciclo do ensino básico. Ministério da Educação e Ciência: Lisboa. Disponível em: https://www. dge.mec.pt/sites/default/files/Curriculo/Aprendizagens Essenciais/2_ciclo/5_matematica_18julho_rev.pdf

NCTM (2000). Principles and Standards for School Mathematics. Reston, VA: NCTM.

Pinheiro, M. G. C., Silva, A. F. G, \& Pietropaolo, R. C. (2018). Conhecimentos de professores sobre a probabilidade. JIEEM, 11(3), 236-244. doi: http://dx.doi.org/10.17921/21765634.2018v11n3p236-244

Pratt, D. (2000). Making sense of the total of two dice. Journal for Research in Mathematics Education, 31(5), 602-625. doi: $10.2307 / 749889$

Watson, J. M. \& Moritz, J. B. (2003). Fairness of dice: A longitudinal study of students' beliefs and strategies for making judgments. Journal for Research in Mathematics Education, 34(4), 270-304. doi: 10.2307/30034785

Wolcott, H. (2009). Writing up qualitative research. Thousand Oaks, CA: SAGE. 